\title{
Estudo sobre a presença do tema "transtorno do espectro do autismo (TEA)" nos currículos de graduação em pedagogia
}

\section{Study on the presence of the theme "autism spectrum disorder (ASD)" in undergraduate pedagogy curricula}

\section{Estudio sobre la presencia del tema "trastorno del espectro autista (TEA)" en los planes de estudio de la pedagogía de pregrado}

Nerise Maia Guazzelli'

https://orcid.org/0000-0003-4404-5I4X

Paula Fontana Fonseca ${ }^{2}$

https://orcid.org/0000-0002-4887-3I 48

\begin{abstract}
Resumo: $O$ presente artigo apresenta o resultado de uma pesquisa que teve por objetivo identificar a presença da temática "transtorno do espectro do autismo (TEA)" nos conteúdos programáticos das disciplinas de graduação dos cursos de pedagogia e extrair, por meio da análise de conteúdo (BARDIN, 1977), as diversas compreensões concernentes ao tema nesses currículos. Para tanto, foram estudadas as ementas das disciplinas dos currículos de graduação em pedagogia de três Instituições de Ensino Superior do município de São Paulo. A partir do procedimento de análise três categorias foram formuladas: aspectos legislativos do TEA; aspectos médico-psicológicos do TEA e aspectos subjetivos do TEA. Foi possível apreender a prevalência, na abordagem ao tema proposta pelas disciplinas, dos aspectos legislativos - que fazem referência à presença da legislação e documentos normativos - e médico-psicológicos - categoria na qual prepondera a definição diagnóstica e de desenvolvimento humano.
\end{abstract}

Palavras-chave: Educação Inclusiva. Transtorno do Espectro do Autismo. Pedagogia.

Abstract: This paper presents the results of a research that aimed to identify the presence of the theme of autism spectrum disorder (ASD) in the programmatic contents of the undergraduate disciplines of pedagogy courses to extract, through content analysis (BARDIN, 1977), the various understandings concerning the theme in these curricula. To this end, we studied the menus of the disciplines of undergraduate curricula in pedagogy of three Higher Education Institutions in the city of São Paulo. From the analysis procedure, three categories were formulated: legislative aspects of the ASD; medical-psychological aspects of ASD and subjective aspects of ASD. It was possible to apprehend the prevalence of legislative aspects - which refers to the presence of legislation

\footnotetext{
' Mestre em Educação pela Universidade Ibirapuera (UNIB). Psicopedagoga. E-mail: nerisemg@yahoo.com.br

${ }^{2}$ Doutora em Educação pela Faculdade de Educação da Universidade de São Paulo (USP). Professora do curso de mestrado em Educação, Subjetividade e Psicanálise da Universidade Ibirapuera (UNIB). E-mail: paulafontanafonseca@gmail.com
}

Olhar de professor, Ponta Grossa, v. 24, p. I-17, e-18405.095, 2021.

Disponível em <https://revistas2.uepg.br/index.php/olhardeprofessor> 
and normative documents - and medical-psychological - a category in which the definition of diagnosis and human development are prevalent - in the approach to the theme proposed by the disciplines.

Keywords: Inclusive Education. Autism Spectrum Disorder. Pedagogy.

Resumen: Este artículo presenta los resultados de una investigación que tuvo como objetivo identificar la presencia del tema del trastorno del espectro autista (TEA) en los contenidos programáticos de las disciplinas de pregrado de los cursos de pedagogía y extraer, a través del análisis de contenido (BARDIN, 1977), los diversos entendimientos sobre el tema en estos planes de estudio. Para ello, estudiamos los planes de las disciplinas de pregrado en pedagogía de tres Instituciones de Educación Superior de la ciudad de São Paulo. A partir del procedimiento de análisis, se formularon tres categorías: aspectos legislativos del TEA; aspectos médicopsicológicos del TEA y aspectos subjetivos del TEA. Fue posible aprehender la prevalencia de aspectos legislativos -que se refieren a la presencia de la legislación y documentos normativos- y médico-psicológicos - categoría en la cual preponderó la definición de diagnóstico y desarrollo humano - en el abordaje del tema propuesto por las disciplinas.

Palabras-clave: Educación Inclusiva. Trastorno del espectro autista. Pedagogía.

\section{Introdução}

O direito à Educação como princípio fundamental coloca em destaque a formação inicial do educador, uma vez que esta formação deve estar alinhada com esse princípio de modo a possibilitar que os professores acolham a diversidade na sala de aula regular. Com isso, percebe-se a necessidade de compreender se os profissionais que atuam na Educação básica possuem uma formação profissional que tenha proporcionado o embasamento teórico necessário para atuarem inclusive com alunos público-alvo da Educação Especial, em particular, alunos diagnosticados com Transtorno do Espectro do Autismo (TEA).

Sabe-se que as diretrizes curriculares dos cursos de Pedagogia seguem a Resolução CNE/CP $\mathrm{n}^{\circ}$ I, de 15 de maio de 2006 (BRASIL, 2006). Nelas, encontramos artigos que citam a diversidade em um aspecto geral, como se segue:

IX - Identificar problemas socioculturais e educacionais com postura investigativa, integrativa e propositiva em face de realidades complexas, com vistas a contribuir para superação de exclusões sociais, étnico-raciais, econômicas, culturais, religiosas, políticas e outras;

$X$ - Demonstrar consciência da diversidade, respeitando as diferenças de natureza ambiental-ecológica, étnico-racial, de gêneros, faixas geracionais, classes sociais, religiões, necessidades especiais, escolhas sexuais, entre outras. (BRASIL, 2006, p.II)

Esse texto, que é anterior à Lei 12.764 que instituiu a "Política Nacional de Proteção dos Direitos da Pessoa com Transtorno do Espectro Autista" (BRASIL, 20I2), mostra a disposição e plasticidade que a graduação em pedagogia deve ter ao visar abarcar temas relacionados à exclusão social e cita, dentre eles, a educação especial como um dos assuntos que deveria ser contemplado.

As leis brasileiras têm contribuído para difundir e promover as práticas inclusivas, tanto nas instâncias públicas como privadas. Nesse sentido, a política de educação inclusiva brasileira, nas últimas 
décadas, tem tido por objetivo proporcionar a efetiva escolarização de todos os alunos, o que possibilitou que novos temas e problemas surgissem como passíveis de serem investigados. Por isso, o presente artigo toma como problema a ser debatido a presença da temática concernente ao TEA na grade curricular dos cursos de pedagogia, de modo a pensar como esse assunto se apresenta na formação inicial dos professores.

Um dado interessante, para pensar a complexidade da questão, é o aumento do número de matrículas na educação especial, que chegou a I,2 milhão em 2018 - um aumento de 33,2\% em relação ao ano de 20I4, considerando a população de 4 a $I 7$ anos desde o ensino infantil até o médio (BRASIL, 2018). Os dados da sinopse estatística da Educação Básica do censo escolar do MEC/INEP (BRASIL, 2018), de 2018, indicam, em tópico sobre a Educação Especial, que o percentual de matrículas de alunos com deficiência, transtornos globais do desenvolvimento ou altas habilidades, em todas as etapas de ensino vem aumentando gradativamente. Se em 2014, o percentual de alunos atendidos era de $87,1 \%$, em 2018 esse número passou para $92,1 \%$. Além disso, o percentual de alunos que frequentam a classe comum e que têm acesso ao atendimento educacional especializado (AEE) também cresceu no período, passando de 37,1\%, em 2014, para 40,0\%, em 2018. Importante destacar que esses números podem refletir os efeitos da promulgação da Lei I2.764/20I2 que instituiu, em 2012, a Política Nacional de Proteção dos Direitos da Pessoa com TEA (BRASIL, 20I2).

Esse aumento de alunos público-alvo da educação especial na sala de aula regular faz com que a temática da formação inicial de professor e a forma como os conteúdos estão sendo trabalhados na graduação em pedagogia ganhem destaque: os currículos dos cursos de Pedagogia têm acompanhado essas mudanças no fazer pedagógico?

A presente pesquisa teve como motivação a constatação de que o conhecimento dos professores que atuam no ensino básico a respeito da escolarização dos estudantes com autismo é insuficiente (CASTRO; GIFFONI, 20I7; ORRÚ, 2003; PIMENTEL; FERNANDES, 20I4; SANINI; BOSA, 20I5). Tal situação evidencia a importância da realização de estudos acerca da presença dessa temática nos cursos de formação inicial de professores, que têm por objetivo geral preparar o graduando de pedagogia para atuar na educação básica - sobretudo na educação infantil e anos iniciais do ensino fundamental. Além disso, houve um avanço no campo das diretrizes curriculares para o curso de Pedagogia que superou a noção de habilitações técnicas, de modo que o discente do curso de pedagogia não teria mais a opção de se capacitar visando atuar junto aos alunos com deficiência. Essa diretriz curricular é consonante com as políticas de educação especial (BRASIL, 2008; BRASIL, 20I2) na perspectiva inclusiva implementadas no território nacional, sobretudo a partir dos anos 2000 quando foram determinados parâmetros para a escolarização em sala regular dos alunos definidos como

Olhar de professor, Ponta Grossa, v. 24, p. I-17, e-18405.095, 2021.

Disponível em <https://revistas2.uepg.br/index.php/olhardeprofessor> 
Estudo sobre a presença do tema "transtorno do espectro do autismo (TEA)"...

público-alvo da Educação Especial, sendo ofertado aos mesmos, de forma complementar, recursos no contraturno.

Com o intuito de termos elementos para aprofundar o debate acerca da presença de tópicos relacionados ao TEA e a forma como esses são contemplados nos cursos de pedagogia, que são responsáveis pela formação inicial do professorado brasileiro, a presente pesquisa se debruçou sobre as ementas das disciplinas de três cursos de graduação em pedagogia. Os resultados obtidos foram analisados segundo o método de análise de conteúdo de Bardin (1977), o que possibilitou que três categorias fossem estabelecidas: aspectos legislativos do TEA; aspectos médico-psicológicos do TEA e aspectos subjetivos do TEA. A análise realizada detectou a prevalência dos aspectos legislativos - que fazem referência à presença da legislação e documentos normativos - e médico-psicológicos - categoria na qual prepondera a definição diagnóstica e de desenvolvimento humano - na abordagem ao tema proposta pelas disciplinas das três Instituições de Ensino Superior cujos currículos foram estudados.

É importante destacar que análise documental de ementas tem suas limitações. Ainda que sejam um documento oficial que apresenta os propósitos do curso, as ementas não conseguem abarcar a dinâmica posta em marcha nas salas de aula mediante a prática docente. Além disso, o fato de o assunto não constar em determinada ementa, não significa necessariamente que não seja trabalhada pelo professor, assim como o fato de constar não garante que o conteúdo seja efetivamente considerado durantes as aulas.

\section{A escolarização de alunos diagnosticados com TEA}

Sobre os desafios específicos na escolarização das crianças diagnosticadas com TEA, um dos fatos trazidos por Bastos (2018) demonstra a particular complexidade desta tarefa: a dificuldade no estabelecimento de uma relação com outros, o que em alguns casos dificulta ou restringe as possibilidades de aprendizagem e interação social. Ainda assim, a aprendizagem se apresenta como um caminho de aposta importante para o trabalho educativo (BASTOS, 2018; RODRIGUES; ANGELUCCI, 2018). Rodrigues e Angelucci (2018), em uma pesquisa realizada para mapear a produção científica em relação à escolarização de alunos com TEA, trazem essa questão afirmando que a maioria dos artigos publicados no período analisado, consideram essencial a mediação do professor para efetivo desenvolvimento dos alunos diagnosticados com TEA.

A inclusão escolar deve respeitar e reafirmar a igualdade de direitos e assegurar a educação escolar para todos. Visando a permanência da matrícula do aluno público-alvo da educação especial, devem ser garantidas condições para a escolarização, considerando suportes e serviços especializados para os alunos (MAZZOTTA; D'ANTINO, 20I I). Para tanto, é necessário que as escolas e as políticas

Olhar de professor, Ponta Grossa, v. 24, p. I-17, e-18405.095, 2021.

Disponível em <https://revistas2.uepg.br/index.php/olhardeprofessor> 
públicas considerem que incluir não se restringe a matricular o aluno com deficiência e colocá-lo na mesma sala que os demais (MANTOAN, 2003).

A perspectiva defendida por Rodrigues e Angelucci (2018) é crítica à proposição de uma prática pedagógica centrada na doença e que tenha por base as limitações do aluno. Prática marcada pela entrada nas diretrizes educacionais de categorias biomédicas que propõem a compreensão do aluno a partir do quadro diagnóstico, deixando em segundo plano o investimento do professor e da própria escola. Conforme as próprias autoras destacam, o campo de produção teórico brasileiro acerca da escolarização de crianças diagnosticadas com TEA é complexo e por vezes contraditório, de modo que são encontrados estudos que focam na centralidade do diagnóstico, outros na prática de ensino e, um terceiro grupo, que dá ênfase para a experiência subjetiva e o laço social que a escolarização permite (RODRIGUES; ANGELUCCI, 20I8). Assim sendo, uma proposta educacional única formulada a partir do quadro de TEA vai, necessariamente, desconsiderar a particularidade de cada criança, pois são suas características biomédicas que definiram a intensidade e diversidade de ações pedagógicas necessárias para seu desenvolvimento no processo educacional.

Maleval (2017, p. 353) constata que quando o assunto é autismo e escolarização há uma grande heterogeneidade em termos de métodos educativos, com prevalência daqueles que visam "melhorar o comportamento social e as capacidades cognitivas". O autor valoriza a importância de se entender - autismo como uma forma específica de constituição subjetiva e ressalta que os próprios autistas devem ser escutados quando o assunto é aprendizagem. Ele realiza uma crítica aos métodos que denomina coercitivos ainda que esses possam efetivamente ter resultados mensuráveis segundo critérios como quociente intelectual (QI). Para o autor, as escolhas dos autistas - suas ilhas de competência e invenções singulares - devem ser respeitadas de modo que a "autonomia resulta de uma escolha que não se ensina" (MALEVAL, 2017, p. 224).

Evidencia-se, assim, a existência de pelo menos duas concepções principais quando o assunto é autismo. Uma delas é fruto da tradição psicanalítica e a outra advém da concepção cognitivista, marcada pelas teorias médicas que consideram o autismo uma patologia caracterizada por déficits em módulos cognitivos (BRASIL, 20I5). No entanto, seja a concepção cognitivista, seja a oriunda da tradição psicanalítica, pode-se afirmar que o transtorno do espectro do autismo exige múltiplas abordagens, de modo que nenhuma se torne exclusiva e se autoproclame como totalizante, acusando as outras de reducionistas (BRASIL, 2015).

Essas afirmações podem ser encontradas no documento "Linha de Cuidado para a Atenção das Pessoas com Espectro Autista e suas Famílias na Rede de Atenção Psicossocial do Sistema Único de Saúde/SUS” (BRASIL, 2015), publicado pelo Ministério da Saúde em 2015, que regulamenta a atenção a pessoa com autismo no âmbito do sistema único de saúde (SUS) brasileiro, Além deste, há 
Estudo sobre a presença do tema "transtorno do espectro do autismo (TEA)"...

também outro documento importante nesse processo de regulamentação do Ministério da Saúde, falamos das "Diretrizes de Atenção à Reabilitação de pessoas com Transtorno do Espectro do Autista (TEA)", de 2014 (BRASIL, 20I4). Ambos os documentos contaram com interlocução de diversas áreas, inclusive com participação de representantes das principais universidades brasileiras, e foram elaborados visando contribuir com a organização da atenção ofertada para a pessoa com autismo no SUS. Entretanto, o documento "Linha de Cuidado" foi submetido à Consulta Pública, o que não aconteceu com o documento "Diretrizes de Reabilitação" (BRASIL, 20I4).

O trabalho de análise comparativa entre esses dois documentos, realizado por Pereira e suas colaboradoras (2016), propôs quatro eixos de análise: os objetivos de ambos os documentos; as concepções de autismo e deficiência presentes em cada um deles; a ideia de detecção precoce que cada um sustenta e a proposta de ordenação de um fluxo de atenção nas redes do SUS no que tange ao autismo. $O$ estudo buscou apresentar convergências e divergências dos dois documentos analisados. Além dos objetivos, outra convergência presente em ambos os documentos é a apresentação da definição de autismo como deficiência pautada na Convenção Internacional dos Direitos das Pessoas com Deficiência que põe ênfase na "noção de relação e interdependência entre os aspectos biológicos e sociais (da cultura)" (PEREIRA et.al, 2016, p.34). Os aspectos biológicos não são negados, mas perdem o status de determinação numa relação causal única. As autoras destacam que, apesar disso, o documento "Linha de Cuidado" acrescenta a importância da singularidade e a necessária proteção contra a fixação de estigmas, demonstrando com isso que a discussão sobre o autismo nas políticas públicas não pode ficar em segundo plano (PEREIRA et al, 2016).

A análise feita pelas autoras, Pereira et al. (2016), aponta a necessidade de sustentar o aspecto subjetivo quando se trata do tema autismo e de propor que o tratamento seja entendido como do âmbito da saúde mental - tal qual proposto no documento "Linha de cuidado" - potencializando a atuação em rede com a área de reabilitação. Defendendo, assim, a permanência dessa noção de sujeito no campo do tratamento ao autismo no que diz respeito ao estabelecimento de uma política pública de atenção à saúde. Entre tantos pontos complexos, pode-se afirmar que esses dois documentos contemporâneos entre si e com pontos conflitantes e divergentes deixam claro que há pouco consenso quando o assunto é diagnóstico, tratamento e escolarização das crianças diagnosticadas como pertencentes ao TEA. Isto traz uma especificidade ao campo da formação inicial de professores: abarcar essa diversidade de pensamento característica da área nos dias de hoje.

Olhar de professor, Ponta Grossa, v. 24, p. I-17, e-18405.095, 2021.

Disponível em <https://revistas2.uepg.br/index.php/olhardeprofessor> 


\section{Método}

Para o desenvolvimento dessa pesquisa inicialmente foi realizada a revisão bibliográfica sobre o tema da educação inclusiva na formação do pedagogo, juntamente com uma discussão teórica acerca do diagnóstico do Transtorno do Espectro do Autismo e dos fundamentos para o trabalho educativo advindos da experiência inclusiva em curso nas escolas atualmente. Esse percurso embasou a discussão dos dados que obtidos na análise dos currículos de três instituições de ensino superior (IESs), com sólida trajetória na formação em pedagogia.

A coleta dos dados foi realizada junto aos currículos dos cursos de Pedagogia de três instituições - sendo uma universidade pública, denominada FF, e duas particulares, denominadas BB e GG - cujas ementas das disciplinas ofertadas no ano de 2018 estavam disponíveis nos sites das IESs ou foram disponibilizadas por e-mailmediante nossa solicitação. Com isso, buscou-se compreender se as graduações têm ou não um currículo que atenda a formação do professor no que se refere à Educação Especial, com ênfase específica para $\circ$ trabalho inclusivo com crianças diagnosticadas como pertencentes ao TEA.

$\mathrm{Na}$ busca realizada nos documentos curriculares das três IESs a temática TEA foi rastreada utilizando como termos da busca: TEA, Autismo, Transtornos Globais do Desenvolvimento (TGD) e Altas Habilidades/superdotação. Esses termos de busca foram definidos com base nos documentos norteadores das políticas de educação especial e inclusiva. Após a seleção das disciplinas que faziam menção direta à temática TEA, procedemos à análise de suas ementas considerando o objetivo proposto para disciplina, seus tópicos de estudo e bibliografia proposta.

Para a análise de dados, foi escolhida a análise de conteúdo. Segundo Bardin (1977), essa modalidade metodológica não deixa de ser uma análise de significados, uma vez que se ocupa em realizar uma descrição objetiva e sistemática do conteúdo extraído do material analisado e sua respectiva interpretação, pois, procura conhecer aquilo que está por trás do significado das palavras; além de fazer menção à análise documental propiciando uma forma de condensação das informações, tanto para consultas como para armazenamento. A categorização discursiva possibilitou que fossem depreendidos elementos que comungam de traços agrupáveis o que permite uma interpretação e discussão dos significados subjacentes aos textos apresentados nas ementas estudadas.

A análise possibilitou que fossem formuladas três categorias: aspectos legislativos do TEA; aspectos médico-psicológicos do TEA e aspectos subjetivos do TEA. A discussão acerca da presença desses aspectos nas disciplinas estudadas permitiu que fossem compreendidos sentidos presentes nos cursos, com ênfase para a importância das leis e normativas que regulamentam a educação especial na 
Estudo sobre a presença do tema "transtorno do espectro do autismo (TEA)"...

perspectiva inclusiva, assim como para a centralidade do debate acerca da categoria diagnóstica biomédica que aparece atrelada ao desenvolvimento humano.

\section{Resultados}

Foi realizada uma busca textual dos termos definidos como critério de inclusão para definição da amostra das ementas do curso de Pedagogia das três IES's. Sete disciplinas foram identificadas como tendo em suas ementas menção direta à temática TEA. O conteúdo programático de cada disciplina era composto fundamentalmente de uma ementa da disciplina, na qual constava um resumo do programa do curso, seus objetivos bem como as referências bibliográficas propostas para abarcar tal conteúdo. O quadro I apresenta os nomes e distribuição das disciplinas nos cursos de graduação em pedagogia das três universidades estudadas.

QUADRO I - disciplinas que fazem referência à temática TEA do currículo de graduação das três Instituições de Ensino Superior: FF, BB e GG.

\begin{tabular}{|l|l|}
\hline \multirow{4}{*}{ Universidade } & Disciplinas que fazem referência à temática TEA \\
\hline \multirow{4}{*}{ FF - pública } & Educação Especial: Fundamentos, Políticas e Práticas Escolares \\
\cline { 2 - 2 } & Projeto Integrado de Estágio em Docência em Educação Especial \\
\cline { 2 - 2 } & $\begin{array}{l}\text { Optativa eletiva I: Educação Especial: abordagens e tendências na } \\
\text { Área da Deficiência Intelectual }\end{array}$ \\
\cline { 2 - 2 } & $\begin{array}{l}\text { Optativa eletiva 2: Educação especial, inclusão escolar e políticas de } \\
\text { atendimento a alunos com deficiência, transtornos globais do } \\
\text { desenvolvimento e altas habilidades/superdotação }\end{array}$ \\
\cline { 2 - 2 } & $\begin{array}{l}\text { Optativa eletiva 3: Educação e Infância Problemática: Elementos de } \\
\text { Psicanálise e Educação Especial }\end{array}$ \\
\hline BB - particular & Educação Inclusiva \\
\hline GG - particular & Educação Inclusiva \\
\hline
\end{tabular}

Fonte: Elaboração das autoras, $2021^{3}$.

Como segunda etapa de análise (Quadro 2), foi realizada a leitura detida das ementas dessas disciplinas e destacados os trechos nos quais havia menção direta à temática TEA, de modo a acessar qual a ênfase dada ao conteúdo no programa. Entendemos que a ementa do curso é um retrato da disciplina, uma proposição disparadora, que não abarca o que efetivamente cada curso abordou. Nesse

\footnotetext{
${ }^{3}$ Os quadros apresentados no presente estudo foram elaborados pelas autoras tendo por base a coleta de dados realizada junto aos currículos dos cursos de Pedagogia de três Instituições de Ensino Superior atuantes no município de São Paulo.
}

Olhar de professor, Ponta Grossa, v. 24, p. I-17, e-18405.095, 202 I.

Disponível em <https://revistas2.uepg.br/index.php/olhardeprofessor> 
sentido, nossa análise acessa a dimensão proposta e não a efetivada (para tal empreendimento uma nova pesquisa com entrevista de professores e alunos seria necessária).

QUADRO 2 - Exemplos selecionados das ementas e bibliografia das disciplinas que fazem referência ao tema TEA em seus programas curriculares nas IESs FF, BB e GG

\begin{tabular}{|c|c|c|}
\hline IES & Disciplinas & Temática TEA na ementa (trechos destacados) \\
\hline \multirow{5}{*}{$\mathbf{F F}$} & $\begin{array}{l}\text { Educação Especial: Fundamentos, } \\
\text { Políticas e Práticas Escolares }\end{array}$ & $\begin{array}{l}\text { - "Apresentar as diretrizes legais da política educacional } \\
\text { brasileira direcionada ao atendimento de alunos com } \\
\text { deficiência, transtornos globais do desenvolvimento e } \\
\text { altas habilidades/superdotação, assim como sua análise } \\
\text { na perspectiva do direito à educação"; } \\
\text { - Política Nacional de Proteção dos Direitos da Pessoa com } \\
\text { Transtorno do Espectro Autista e altera o } \S 30 \text { do art. } \\
98 \text { da Lei n. } 8.112 \text {, de } 11 \text { de dezembro de } 1990 \text {. } \\
\text { - Decreto no. } 8.368 \text {, de } 02 \text { de dezembro de } 2015 . \\
\text { Regulamenta a Lei no. I2.764, de } 27 \text { de dezembro de } 2012 \text {, } \\
\text { que institui a Política de Proteção dos Direitos da Pessoa } \\
\text { com Transtorno do Espectro Autista. }\end{array}$ \\
\hline & $\begin{array}{l}\text { Projeto Integrado de Estágio em } \\
\text { Docência em Educação Especial }\end{array}$ & $\begin{array}{l}\text { - BRASIL. Decreto no. } 8.368 \text {, de } 02 \text { de dezembro de } 2014 \text {. } \\
\text { Regulamenta a Lei no. } 12.765 \text {, de } 27 \text { de dezembro de } 2012 \text {, } \\
\text { que institui a Política de Proteção dos Direitos da Pessoa } \\
\text { com Transtorno do Espectro Autista. Brasília, 2014. }\end{array}$ \\
\hline & Optativa eletiva I & $\begin{array}{l}\text { - BRASIL. Lei n. } 12.764 \text {, de } 27 \text { de dezembro de } 2012 \text {. Institui } \\
\text { a Política Nacional de Proteção dos Direitos da Pessoa com } \\
\text { Transtorno do Espectro Autista e altera o } § 30 \text { do art. } \\
98 \text { da Lei n. }{ }^{\circ} 8.1 \text { I I2, de II de dezembro de } 1990 \text {. Diário } \\
\text { Oficial da União, Brasília, DF, } 28 \text { dez. } 2012 \text {, Seção I, Página } 2 \\
\text { (Publicação Original). } \\
\text { - BRASIL. Decreto no. } 8.368 \text {, de } 02 \text { de dezembro de } 2015 . \\
\text { Regulamenta a Lei no. } 12.764 \text {, de } 27 \text { de dezembro de } 2012 \text {, } \\
\text { que institui a Política de Proteção dos Direitos da Pessoa } \\
\text { com Transtorno do Espectro Autista. Diário Oficial da } \\
\text { União, Brasília, DF, } 3 \text { dez. 20I4, Seção I, Página } 2 \text { (Publicação } \\
\text { Original). }\end{array}$ \\
\hline & Optativa eletiva 2 & $\begin{array}{l}\text { - "Esta disciplina visa a proporcionar aos estudantes } \\
\text { elementos para a compreensão e análise de políticas públicas, } \\
\text { legislação, planos e programas governamentais no Brasil para } \\
\text { o atendimento escolar de alunos com deficiência, } \\
\text { transtornos globais do desenvolvimento e altas } \\
\text { habilidades/ superdotação" } \\
\text { - BRASIL. Lei n. I2.764, de } 27 \text { de dezembro de } 2012 \text {. Institui } \\
\text { a Política Nacional de Proteção dos Direitos da Pessoa com } \\
\text { Transtorno do Espectro Autista e altera o } \$ 30 \text { do art. } \\
98 \text { da Lei n. } 8.1 \text { II2, de II de dezembro de 1990. Diário } \\
\text { Oficial da União, Brasília, DF, } 28 \text { dez. } 2012 \text {, Seção I, Página } 2 \\
\text { (Publicação Original). }\end{array}$ \\
\hline & Optativa eletiva 3 & $\begin{array}{l}\text { - KUPFER M.C. (org.). (2000b). - Tratamento e escolarização } \\
\text { de crianças com distúrbios globais do desenvolvimento. } \\
\text { Coleção Psicanálise da Criança. Salvador: Ágalma }\end{array}$ \\
\hline
\end{tabular}


Estudo sobre a presença do tema "transtorno do espectro do autismo (TEA)"...

\begin{tabular}{|l|l|l|}
\hline BB & Educação Inclusiva & $\begin{array}{l}\text { - "Unidade 2 - Deficiência e alunos com necessidades } \\
\text { educacionais especiais 2.2 O que são condutas típicas 2.2.I } \\
\text { Condutas típicas mais descritas; 2.3 Alunos com altas } \\
\text { habilidades/superdotação;"” }\end{array}$ \\
\hline GG & $\begin{array}{l}\text { - "Desenvolvimento Humano: aspectos gerais, Transtorno } \\
\text { do Espectro do Autismo (TEA) - definição, histórico e } \\
\text { questões do desenvolvimento" } \\
\text { - Altas habilidades e superdotação: definição e aspectos } \\
\text { Socioafetivos }\end{array}$ \\
\hline
\end{tabular}

Fonte: Elaboração das autoras, 2021.

Os trechos destacados em negrito justificaram a inclusão da disciplina para a etapa de análise que buscou acessar as concepções presentes nas ementas acerca do tema. Em consideração à análise dos conteúdos, eles foram agrupados de acordo com as similaridades dos elementos (BARDIN, 1977) e foram estabelecidas três categorias: aspectos legislativos do TEA; aspectos médico-psicológicos do TEA e aspectos subjetivos do TEA.

\section{Discussão}

A seguir apresentaremos a discussão empreendida em cada uma das três categorias formuladas a partir dos resultados obtidos junto à pesquisa realizada nas matrizes curriculares do curso de pedagogia de três Instituições de Ensino Superior, sendo uma instituição pública e duas particulares.

I) aspectos legislativos do TEA: refere-se a presença de elementos relacionados às políticas públicas, leis e documentos norteadores nacionais para a atenção e escolarização da pessoa com TEA. Assim, para formulação da categoria, observamos a recorrência da referência à legislação e documentos nas diversas ementas analisadas, incluindo para a análise os documentos que versavam sobre o tema da educação especial e/ou inclusiva.

Conforme demonstrado no quadro 2 , a referência aos aspectos legais se deu sobretudo nas referências bibliográficas que constam nas ementas das disciplinas. Na disciplina obrigatória "Educação Especial: Fundamentos, Políticas e Práticas Escolares" consta que o objetivo é "apresentar as diretrizes legais da política educacional brasileira direcionada ao atendimento de alunos com deficiência, transtornos globais do desenvolvimento e altas habilidades/superdotação", a ênfase é colocada, portanto, no direito à educação dos alunos que são público-alvo da educação especial. $\bigcirc$ mesmo acontece na eletiva "Educação especial, inclusão escolar e políticas de atendimento a alunos com deficiência, transtornos globais do desenvolvimento e altas habilidades/superdotação" que visa proporcionar uma "análise de políticas públicas, legislação, planos e programas governamentais no Brasil para o atendimento escolar de alunos com deficiência, transtornos globais do desenvolvimento e altas habilidades/superdotação". Ambas as disciplinas são ofertadas pela IES FF e colocam ênfase na 
análise da legislação e no direito à educação. Esse aspecto fica explicitado tanto no nome, uma vez que ambas trazem o termo política, como na ementa programática e nas referências bibliográficas. Ambas também têm em sua bibliografia o estudo sobre a Declaração de Salamanca (ONU, 1994) e contemplam a lei 9.394/96 - Lei de Diretrizes e Bases da Educação Nacional (BRASIL, 1996).

A disciplina "Educação Inclusiva", ofertada pela IES GG, ainda que não mencione leis e declarações em suas referências bibliográficas básicas ou complementares, contempla tal conteúdo nos subtópicos da unidade de ensino intitulada "direitos humanos: educação como direito de todos" segunda unidade programática a ser abordada segundo o detalhamento disponível no plano de ensino. Como exemplos elencados nessa unidade programática temos o estudo aceca dos impactos dos marcos internacionais na legislação brasileira de inclusão e a menção à Declaração de Salamanca (ONU, 1994), dentre outros documentos que versam sobre o direito à Educação para Todos.

Dessa forma, a presença de elementos reunidos nessa categoria foi observada nas ementas e/ou bibliografias de todas as IES. Esse resultado pode ser considerado positivo, visto que a inserção e difusão das leis de proteção e direito à educação das pessoas diagnosticadas com autismo gerou implicações na formulação do arcabouço teórico das disciplinas e, consequentemente, isso indica que as IES's estudadas têm pretensão de apresentar o fundamento legal da inclusão aos discentes. No entanto, como aponta Mantoan (2003, p.2I), a legislação pode sofrer interpretações tendenciosas "reduzindo-a unicamente à inserção de alunos com deficiência no ensino regular". O que faz com que a presença desse aspecto seja importante, mas não suficiente se a intenção é promover uma formação docente que vise a escola inclusiva.

Houve um importante avanço, marcadamente fruto da declaração de Salamanca (ONU, 1994), em 1994, e da convenção da Guatemala (OEA, 1999), em 1999, nas diretrizes acerca da educação especial no Brasil. Nos primeiros anos do século XXI, portanto, se consolidou um arcabouço de marcos legais e normativas que visavam garantir o direito à educação para todos com uma política de educação especial na perspectiva inclusiva. Assim, é possível afirmar que os aspectos legais são preponderantes na implementação e manutenção desta perspectiva inclusiva que garante a escolarização em classe regular para todo e qualquer aluno matriculado na escola.

Quanto à especificidade da temática TEA, encontramos a recorrência da menção à lei de 2012 que institui a Política Nacional de Proteção dos Direitos da Pessoa com Transtorno do Espectro Autista (BRASIL, 20I2).

2) aspectos médico-psicológicos do TEA: essa categoria visou reunir os conteúdos referentes aos manuais médicos que categorizam e descrevem o quadro psicopatológico do TEA buscando uma definição nosográfica, ela também contempla elementos que dizem respeito ao desenvolvimento 
Estudo sobre a presença do tema "transtorno do espectro do autismo (TEA)"...

humano, seus aspectos orgânicos e cognitivos. Elementos pertencentes a essa categoria foram identificados em todas as três IES.

As disciplinas que abordam esses aspectos visam uma definição do quadro de autismo, especificando seu desenvolvimento e quais seriam as condutas típicas do transtorno. $O$ termo transtorno ganha relevância nesta análise pois ele deflagra essa concepção médica que se soma à ideia de desenvolvimento, própria do campo psicológico. Foi esta dupla incidência que se destacou de modo a nomear a categoria. Essa categoria aponta para a atualidade e relevância de discussões acerca do estatuto do aluno na escola inclusiva que, conforme afirma Mantoan (2003, p. 20), "não tem uma identidade fixada em modelos ideais, permanentes, essenciais".

Como exemplos paradigmáticos desta categoria temos as duas disciplinas nomeadas "Educação Inclusiva" - sendo uma ofertada pela IES BB e a outra, de mesmo nome, pela IES GG. A disciplina oferecida pela IES BB tem como segunda unidade programática "Deficiência e alunos com necessidades educacionais especiais", a qual conta com uma lista das deficiências - física, intelectual, visual, auditiva - a serem abordadas ao longo do semestre além do estudo sobre alunos com altas habilidades/superdotação. Já na disciplina da GG, a primeira unidade programática, "desenvolvimento humano: aspectos gerais", aborda a classificações da deficiência na área da saúde além da definição e questões do desenvolvimento das deficiências sensoriais, físicas, intelectual, TEA e outras síndromes.

Esse aspecto é consonante com o debate ao qual fizemos referência ao abordarmos, sobretudo, os dois documentos, contemporâneos entre si: "Diretrizes de Atenção à Reabilitação de pessoas com Transtorno do Espectro do Autista (TEA)" e "Linha de Cuidado para a Atenção das Pessoas com Espectro Autista e suas Famílias na Rede de Atenção Psicossocial do Sistema Único de Saúde/SUS". Em nossa discussão acerca dos dois documentos, destacamos a existência de pontos conflitantes e divergentes que indicavam o pouco consenso quando o assunto é diagnóstico, tratamento e escolarização das crianças diagnosticadas como pertencentes ao TEA. Além disso, o trabalho de Rodrigues e Angelucci (2018) já havia apontado a centralidade da categoria diagnóstica biomédica quando o assunto é escolarização de crianças com TEA.

De maneira geral, observou-se nas ementas maior espaço destinado aos assuntos dessa categoria em relação à categoria aspectos subjetivos do TEA - que apresentaremos na sequência deste trabalho. Essa é uma questão importante a ser discutida, na medida em que a ideia do autismo como deficiência ou transtorno psíquico se apresenta como característica prevalente na discussão proposta por disciplinas que tratam explicitamente da Educação Inclusiva. Ou seja, há uma ênfase no debate diagnóstico e categorial em detrimento de outros aspectos concernentes à escolarização do aluno com TEA.

Olhar de professor, Ponta Grossa, v. 24, p. I-17, e-18405.095, 202 I.

Disponível em <https://revistas2.uepg.br/index.php/olhardeprofessor> 
A presença da caracterização biomédica do TEA não deixa de ter relação com os aspectos legislativos uma vez que toda política de educação especial e inclusiva precisa definir seu público-alvo e o faz recorrendo à nosografia médica (RODRIGUES; ANGELUCCI, 20I8).

Nessa lógica, é relevante o estudo dos fundamentos básicos e da evolução histórica do quadro de autismo, de maneira a fundamentar a compreensão de outros conceitos que se edificaram nessa primeira visão do TEA. Assim, essa categoria revela que a discussão dos conteúdos sobre autismo é considerada essencial, o que legitima a presença de textos clássicos a fim de permitir aos alunos uma introdução ao universo autístico, o que nos leva à terceira categoria;

3) aspectos subjetivos do TEA: essa terceira categoria foi formulada tendo por base os elementos presentes na disciplina optativa eletiva 3 "Educação e Infância Problemática: Elementos de Psicanálise e Educação Especial”, ofertada pela IES FF. Esta disciplina congrega autores psicanalistas que tratam do tema da educação inclusiva em uma perspectiva subjetiva. Ainda que a ementa não faça referência ao TEA em sua descrição, pudemos encontrar ao menos uma referência bibliográfica na qual esta temática estava presente.

Em uma análise mais detida da ementa, encontramos que seu objetivo é partir das "teses psicanalíticas sobre o tempo da infância como momento constitutivo da subjetividade" de modo a "reconsiderar o algoritmo psicológico desenvolvimentista" e contribuir com o "debate atual em torno das vicissitudes e impasses experimentados na inclusão escolar de crianças com necessidades educativas especiais". Assim, ainda que não faça uso da terminologia TEA, preferindo necessidades educativas especiais, a ementa cita vários autores psicanalistas consagrados na temática TEA como Kupfer, Lajonquière, Mannoni. É nesse cenário que está inserido o debate em torno das vicissitudes e impasses experimentados na inclusão escolar de crianças e adolescentes com autismo. Além disso, a disciplina se propõe a realizar uma crítica ao aspecto desenvolvimentista, diferenciando-se, desse modo, dos aspectos médico-psicológicos abordados em nossa segunda categoria.

Esta é a única disciplina que faz referência à teoria psicanalítica e ao que abordamos como sendo do âmbito da experiência subjetiva e sua relação com o laço social promovido pela escolarização (RODRIGUES; ANGELUCCI, 20I8). Há uma proposta de problematização que visa inverter a equação: diagnosticar para educar. Além disso, está presente a articulação de uma matriz clínica junto ao cunho educativo, tema enfatizado por Bastos (2018) e Maleval (2017).

É interessante notar que em nossas análises formulamos três categorias nas quais a temática da escolarização de alunos com TEA esteve presente seja em função das políticas públicas e legislação específica, seja na abordagem dos aspectos nosográfico, psicopatológico e de desenvolvimento psicológico - que nomeamos como médico-psicológicos - ou ainda na articulação da clínica com o 
Estudo sobre a presença do tema "transtorno do espectro do autismo (TEA)"...

campo educativo, visando garantir a preponderância da singularidade de cada criança no estabelecimento do laço social propiciado pela inclusão escolar.

\section{Considerações finais}

A presente pesquisa procurou conhecer e identificar como a temática do TEA está presente nos currículos de pedagogia de três Instituições de Ensino Superior atuantes no município de São Paulo e quais compreensões são abarcadas na formação inicial desses pedagogos. Para tanto, foram analisadas ementa de sete disciplinas selecionadas no programa curricular, do ano de 2018 , das três Universidades, sendo uma pública e duas particulares.

Com o objetivo de analisar a presença de conteúdos sobre autismo nos currículos de graduação na formação de professores das três instituições estudadas, empreendemos uma análise de conteúdo (BARDIN, 1977) da qual foi possível extrair três categorias prevalentes: I) aspectos legislativos do TEA; 2) aspectos médico-psicológicos do TEA e 3) aspectos subjetivos do TEA.

Entre as principais características dos elementos curriculares destacados neste estudo está a predominância dos aspectos legislativos e, na sequência, há a presença da discussão acerca da caracterização biomédica e desenvolvimentista do TEA. A categoria que abarca os aspectos subjetivos ficou restrita à apenas uma disciplina que tinha como referencial teórico principal o psicanalítico.

Nosso estudo identificou que nas três IESs participantes há o oferecimento aos graduandos de disciplinas que abarcam o tema do autismo, sendo que o tema comparece como subárea da educação especial e/ou inclusiva. Nosso intuito não foi o de avaliar se a forma como a temática TEA é ensinada nos três cursos prepara o professor para sua atuação profissional nas salas regulares de ensino. Ainda assim, é possível identificar que a oferta da temática se encontra restrita à poucas disciplinas e que estas dão ênfase aos aspectos legais e diagnósticos acerca do TEA. Outro ponto a ser destacado é que o curso da Universidade pública tem mais disciplinas que abordam o tema, sendo que nas duas Universidades particulares havia apenas uma disciplina, em cada uma, delas que abarcasse o tema. É digno de nota que o curso da Universidade pública tem sua grade curricular composta de disciplinas obrigatórias e optativas o que permite ao graduando a opção de aprofundar certos temas.

A análise de conteúdo permitiu-nos acessar que a temática TEA é abordada nas ementas estudadas segundo três aspectos preponderantes: legislativos, médico-psicológicos e subjetivos. É possível compreender que a discussão acerca da escolarização e experiência educativa de alunos com TEA esteja vinculada, predominantemente, seja ao aspecto legislativo - com ênfase nas leis e normativas que garantem o acesso do aluno à educação -, seja ao aspecto médico-psicológico - que busca a definição de comportamentos e parâmetros de desenvolvimento da pessoa diagnosticada com autismo.

Olhar de professor, Ponta Grossa, v. 24, p. I-17, e-18405.095, 2021.

Disponível em <https://revistas2.uepg.br/index.php/olhardeprofessor> 
Esses aspectos são abordados como unidades curriculares que antecedem a discussão sobre a função da escola e o trabalho do professor na escolarização de todos os alunos na sala regular. Os estágios e estudos de caso são indicados em três das ementas como forma de contemplar a diversidade dos alunos no trabalho educativo, mas não há nesse tópico qualquer menção direta ao TEA em nenhuma das disciplinas estudadas.

Por fim, o presente estudo apresenta como limitação o fato de ter se baseado exclusivamente em análise documental (programas curriculares) de três Instituições de Ensino Superior. Os resultados desta pesquisa não são passíveis de generalizações para outras universidades ou instituições com a mesma vocação, uma vez que foram postulados a partir do estudo de caso de três realidades particulares. Ainda assim, o estudo evidencia a preponderâncias de sentidos presentes na formação inicial dos professores que, em grande parte, vão atuar nas salas regulares da educação básica regidas pelo princípio de uma educação para todos. Concluímos pela importância de que estudos como este e com maior abrangência sejam realizados a fim de termos uma análise que aborde o complexo contexto brasileiro.

\section{Referências}

BARDIN, L. Análise de Conteúdo. Lisboa: Edições 70, 1977.

BASTOS, M. B. Sobre a Escuta de Professores na Formação Docente. In: VOLTOLINI, R. (org.). Psicanálise e formação de professores: antiformação docente. São Paulo: Zagodoni, 2018.

BRASIL. Ministério da Educação. LEI N 9.394 de 20 de dezembro de 1996, Brasília: MEC, 1996. Disponível em: http://portal.mec.gov.br/seesp/arquivos/pdf/lei9394_Idbnl.pdf Acesso em: 10 jan. 2021.

BRASIL. Ministério de Educação. Diretrizes Curriculares Nacionais para o Curso de Graduação em Pedagogia, licenciatura. Resolução CNE/CP I/2006. Brasília: Diário Oficial da União, 2006. Disponível em: rcp002_19 (mec.gov.br) Acesso em 20 set, 2021.

BRASIL. Ministério da Educação. Política nacional de educação especial na Perspectiva da educação inclusiva. Brasília: MEC 2008. Disponível em: EDUCAO INCLUSIVA: POLTICA NACIONAL DE EDUCAO ESPECIAL (mec.gov.br) Acesso em 10 ago, 2020.

BRASIL. Ministério da Educação. Lei $\mathbf{n}^{\circ}$ I 2.764, de 27 de dezembro de 20 I 2. Institui a Política Nacional de Proteção dos Direitos da Pessoa com Transtorno do Espectro Autista; e altera o $\S 3^{\circ}$ do art. 98 da Lei 8.II2, de II de dezembro de 1990. Brasília: MEC, 2012.

BRASIL. Ministério da Saúde. Secretaria de Atenção à Saúde. Departamento de Ações Programáticas Estratégicas. Diretrizes de Atenção à Reabilitação da Pessoa com Transtornos do Espectro do Autismo (TEA). - Brasília: Ministério da Saúde, 20I4. Disponível em: https://bvsms.saude.gov.br/bvs/publicacoes/diretrizes_atencao_reabilitacao_pessoa_autismo.pdf Acesso em 10 jan. 202I. 
BRASIL. Ministério da Saúde. Linha de cuidado para a atenção às pessoas com transtorno do espectro do autismo e suas famílias na Rede de Atenção Psicossocial do Sistema Único de Saúde. Departamento de Atenção especializada e Temática. Brasília: Ministério da saúde, 2015. Disponível em:

https://bvsms.saude.gov.br/bvs/publicacoes/linha_cuidado_atencao_pessoas_transtorno.pdf Acesso em: 10 ago. 2020.

BRASIL. Ministério da Educação. Resumo técnico do Censo da Educação Básica 2018. Instituto Nacional de Estudos e Pesquisas Educacionais Anísio Teixeira. Diretoria de Estatísticas Educacionais. Brasília: MEC, 2018. Disponível em:

http://download.inep.gov.br/educacao_basica/censo_escolar/resumos_tecnicos/resumo_tecnico_cens o_educacao_basica_2018.pdf Acesso em: 29 abr. 2019.

CASTRO, A. C. D, GIFFONI, S. D. A. O conhecimento de docentes de educação infantil sobre o transtorno do espectro autístico. Revista Psicopedagogia, São Paulo, v. 34, n. 103, p. 98-106, 20 17. Disponível em: https://pt.scribd.com/document/4955679/2/Revista-Estudos-Interdisciplinaresem-Saude-e-Educac-a-o-2020 Acesso em 10 ago. 2020.

MALEVAL, J-C. O autista e a sua voz. Trad. Paulo Sérgio de Souza Jr. São Paulo: Blucher, 2017.

MANTOAN, M. T. E. Inclusão Escolar: O que é? Por quê? Como fazer? São Paulo: Moderna, 2003.

MAZZOTTA, M. J. S.; D’ANTINO, M. E. F. Inclusão social de pessoas com deficiências e necessidades especiais: cultura, educação e lazer. Saúde e Sociedade, São Paulo, v. 20, n 2, p. 377 389, 20I I. Disponível em: https://www.scielosp.org/article/sausoc/20I I.v20n2/377-389/pt/ Acesso em 10 jan. 2021.

OEA - ORGANIZAÇÂO DOS ESTADOS AMERICANOS. Convenção Interamericana para a Eliminação de Todas as Formas de Discriminação contra as Pessoas Portadoras de Deficiência. Conselho Permanente da Organização dos Estados Americanos, Guatemala, 26 de maio de 1999.

ONU - ORGANIZAÇÃO DAS NAÇÕES UNIDAS. Declaração de Salamanca. Salamanca, Espanha, 1994. Disponível em: http://portal.mec.gov.br/seesp/arquivos/pdf/salamanca.pdf Acesso em 10 jan. 2021.

ORRÚ, S. E. A formação de professores e a educação de autistas. Revista lberoamericana de Educación, v. 3I, p. 0I-I5, 2003. Disponível em: https://rieoei.org/historico/deloslectores/391Orru.pdf Acesso em: 10 jan. 2021.

PEREIRA, C., MASCARENHAS, C., PISANESCHI, E., ARAUJO, G., AMANCIO, L., KATZ, I. Construções e comentários sobre os documentos Linha de Cuidado para a Atenção das Pessoas com Espectro Autista e suas Famílias na Rede de Atenção Psicossocial do Sistema Único de Saúde/SUS e Diretrizes de Atenção à Reabilitação de pessoas com Transtorno do Espectro do Autista (TEA). Analytica, São João Del-Rei, v. 5, n 9, p. 3l -40, 20I6. Disponível em: http://pepsic.bvsalud.org/pdf/analytica/v5n9/03.pdf. Acesso em II jan. 202I.

PIMENTEL, A. G. L.; FERNANDES, F. D. M. A perspectiva de professores quanto ao trabalho com crianças com autismo. Audiol., Commun. Res., São Paulo, v. 19, n. 2, p. I7I-178, 20I4. Disponível em:

Olhar de professor, Ponta Grossa, v. 24, p. I-17, e-18405.095, 202 I.

Disponível em <https://revistas2.uepg.br/index.php/olhardeprofessor> 
http://www.scielo.br/scielo.php?script=sci_arttext\&pid=S23 I 7643 I $20|4000200|$ I $\mid$ I \&lng=en\&nrm=iso Acesso em: 10 ago. 2020.

RODRIGUES, I. de B.; ANGELUCCI, C. B. Estado da arte da produção sobre escolarização de crianças diagnosticadas com TEA. Psicol. Esc. Educ., Maringá, v. 22, n.3, p.545-555, dez. 2018. Disponivel em: https://www.scielo.br/j/pee/a/qRctXB5th8MkZ4t9FtFM9Gq/abstract/?lang=pt Acesso em 10 ago. 2020.

SANINI, C., BOSA, C. A. Autismo e inclusão na educação infantil: crenças e autoeficácia da educadora. Revista Estudos de Psicologia, Natal, v. 20, n. 3, p 173-183, jul./set. 2015. Disponível em: https://www.scielo.br/j/edur/a/6vvZKMSMczy9w5fDqfN65hd/ Acesso em 10 ago.2020.

Recebido em: 15 de julho de 2021.

Versão corrigida recebida em: 29 de novembro de 202I.

Aceito em: 17 de dezembro de 202I.

Publicado online em: 22 de dezembro de 2021. 